\title{
Modelling gender perception of quality in interurban bus services
}

$1 \quad$ Marta Rojo CEng Lecturer, University of Burgos, Spain

2 Hernan Gonzalo-Orden PhD, CEng Professor of Transport, University of Burgos, Spain
$3 \quad$ Luigi dell'Olio MEng, PhD, CEng Professor of Transport, University of Cantabria, Santander Cantabria, Spain

4 Angel Ibeas PhD, CEng

Professor of Transport, University of Cantabria, Santander Cantabria Spain
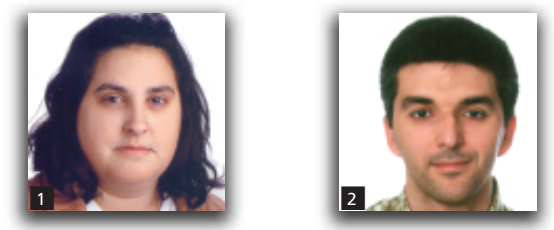

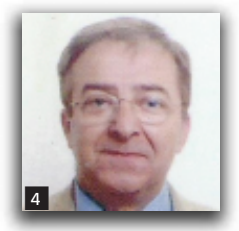

This paper models how women and men perceive the quality of interurban bus services and proposes a new methodology for detecting the highest priority service variables to act on. Service quality perception was modelled using both ordered logit and ordered probit models using data from revealed preference surveys. The methodology for detecting different priority levels uses the graphic representation of the relationships between influence in the model and average evaluation by users. The modification of certain variables increases the knowledge of how woman evaluate quality in bus services to help promote the use of interurban public transport. Statistical analysis of the data provides some conclusions such as: the proportion of users increases as age decreases for both men and women; and women seem to make shorter and more frequent trips than men. The best model for this data set was ordered logit. As expected, the most relevant variable is the relationship between quality and price. Other important variables are the condition of the bus and the frequency of service.

\section{Introduction}

The importance given to transport sustainability in current society has resulted in increasing encouragement to use public transport as opposed to private (Nurdden et al., 2007).

Improving the quality of service provided for both urban and interurban passengers continues to grow in importance. Operating companies worry about the comfort of their customers and try to offer a better quality of service at ever more competitive prices.

The encouragement of public transport is nothing new and many examples can be found in the literature on the subject. For example, in the 1980s Cherniack (1981) proposed the fixing of two different fare ranges - a lower fare for low-income users and a higher fare for higher frequencies and greater comfort on the bus - so that each user could find their ideal fare, thereby increasing use of the service.

Unfortunately the actions taken do not usually produce the desired result, either because the users do not understand them correctly or because they do not value them highly enough.
International experience on this matter shows that studies normally relate the quality of each service variable with the importance placed on it by each user (Foote and Stuart, 1998; Foote et al., 2001; Glascock, 1997).

There have even been attempts to include quality of service in the conditions for service tenders in order to increase demand and thereby reduce future subsidies (Hensher and Houghton, 2004; Hensher and Stanley, 2003; Hensher et al., 2003).

The objective of this study was to note the different behaviour between male and female users, and to design a model which reflected how they valued the different service variables contributing to their overall satisfaction. The use of public transport can be encouraged and the quality of life improved for everybody by using available resources to improve only the most relevant variables towards a more sustainable transport system.

No other relevant research work has been found which specifically looks at the perception of quality according to the gender of the user. Very few studies have been done providing such a thorough analysis considering such a large number of variables 
turning out to be so important from both a statistical and practical point of view. Some studies which looked at the behaviour of the sexes when deciding to travel do exist, for example the studies by Pazy et al. (1996), Hamilton and Jenkins (2000), JohanssonStenman (2002), Matthies et al. (2002) and Schmucki (2002) but none of them looked at behaviour when using interurban public transport.

The present methodology used a survey carried out on bus users. An initial statistical analysis of the data obtained in the survey highlighted the main differences between men and women who use interurban public transport in a different way. Different discrete choice models were tested to relate individual valuation of each variable with overall satisfaction levels in order to determine which were the most relevant and how to manage them.

The study area was Castilla y León which is the most extensive yet one of the least densely populated regions in Spain.

The paper is divided into the following sections: the general methodology followed is presented in Section 2 with references to the main studies performed on the quality of service in public transport introducing the models used and justifying their choice. Section 3 presents the data collection process and their statistical analysis. The models used are presented and estimated in Sections 4 and 5 and a methodology is developed to value the relevant variables in Section 6. The conclusions are presented in Section 7.

\section{Methodology}

General user satisfaction with a public transport system is clearly related to different service variables and is also influenced and modified by the personal characteristics of each user. This study was particularly interested in determining the differences in behaviour of female and male users.

However, it is not so clear how to define which of these characteristics has the most influence and how they modify the overall perception of the service.

A review of the available bibliography on this matter reveals that the more commonly used methods employ linear or non-linear regression models. These include a series of variables to determine the overall service quality for comparison with the level of service perceived by the user (see SERVQUAL in Wen et al., 2005) or their influence on passenger demand (Balcombe et al., 2004).

Discrete choice models are also applied in modelling travel behaviour, but they are specially focused on stated preferences experiments (Ortúzar and Garrido, 2000) with or without ordinal specification.

Train (2003) proposes a mixed-logit model to estimate ordered data, under the assumption that the parameters vary randomly in the population.

The present research applied ordinal (ordered logit and probit) models to the revealed preference experiment to identify which variables had most influence in the overall perception of service quality.

This type of model was chosen because the dependent variable (the overall service quality) is ordinal in nature, so a simple regression would not progress.

A comparison has also been made between the importance and the evaluation of the significant variables of the chosen model. By starting off with the methodology proposed by the Chicago Transit Authority (Foote and Stuart, 1998) and then introducing some novel changes, a graph has been produced combining the representation of the parameter value with the evaluation supplied by the interviewees. After dividing this graph into zones, the variables can then be divided up depending on their priority of action.

The methodology used in this study goes through four phases: data collection, statistical analysis, model building and comparison importance-evaluation.

\section{Data collection and statistical analysis}

Personal interviews were conducted at each bus station in all nine of the region's provincial capitals; this was very labour-intensive fieldwork.

The questions asked in the survey were related to personal information, journey data, scoring different service variables and overall satisfaction. A questionnaire card was prepared for the interviewees to fill in. A sketch of all variables in the survey is presented in Figure 1.

A total of 1319 surveys were then coded (as shown in Table 1). Cleaning the data reduced the final number of surveys to 1011 .

This section contains an initial analysis on the behaviour of men and women on interurban bus journeys. The main differences between male and female behaviour were analysed to find the proportion of travellers distributed by sex, age, frequency and length of trip.

The number of women interviewed (657) represented $65 \%$ and the men (354) $35 \%$ of the sample. As this was a representative sample of the user population, the proportions remained similar for the total number of users. The first conclusion from this is that women used the service more than men, which is a common result in most of the studies on this subject.

By examining the age distribution of the interviewees for both men and woman, it can be seen that the proportion of users 


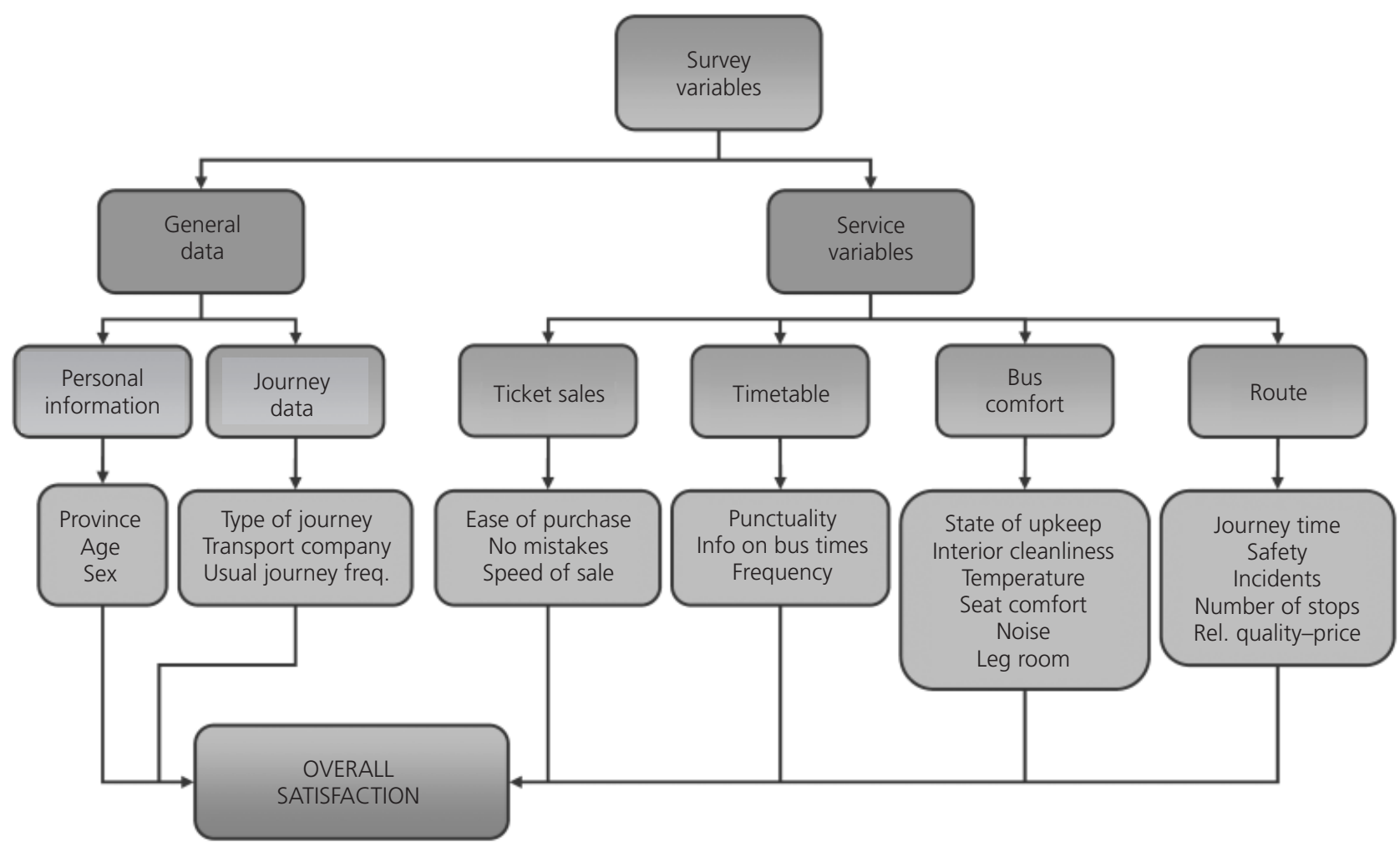

Figure 1. Variables influencing user satisfaction

\begin{tabular}{|c|c|c|c|}
\hline Group & Subgroup & Variable & Coding \\
\hline \multirow[t]{6}{*}{$\begin{array}{l}\text { General } \\
\text { data }\end{array}$} & \multirow[t]{3}{*}{$\begin{array}{l}\text { Personal } \\
\text { information }\end{array}$} & Provinces & $\begin{array}{l}1(\mathrm{AV}), 2(\mathrm{BU}), 3(\mathrm{LE}), 4(\mathrm{PA}), 5(\mathrm{SA}), 6(\mathrm{SG}), 7(\mathrm{SO}), 8(\mathrm{VA}) \\
\text { or } 9(\mathrm{ZA})\end{array}$ \\
\hline & & Age & $\begin{array}{l}20(15-24), 30(25-34), 40(35-44), 50(45-54), 60 \text { (55- } \\
64) \text { or } 70(+65)\end{array}$ \\
\hline & & Sex & 0 (woman) or 1 (man) \\
\hline & \multirow[t]{3}{*}{ Journey data } & Type of journey & 1 (provincial), 2 (inter-provincial) or 3 (inter-regional) \\
\hline & & Transport company & Correlatively (from 1 to 39 ) \\
\hline & & Usual frequency of journey & $1,6,16$ or 30 (trips/month) \\
\hline \multicolumn{2}{|c|}{ Service variables } & \multicolumn{2}{|c|}{1 (very bad), 2 (bad), 3 (average), 4 (good) or 5 (very good) } \\
\hline \multicolumn{2}{|c|}{ Overall satisfaction } & \multicolumn{2}{|c|}{1 (very bad), 2 (bad), 3 (average), 4 (good) or 5 (very good) } \\
\hline
\end{tabular}

Table 1. Coding the survey

diminished as age increased. The data were grouped into age ranges of 10 years, as described in Table 1. The average age of all users was about 35 years.

The age range covering younger people showed the proportion of women to be slightly higher, whereas for the middle-aged population (from 35 to 44 years old) the proportion of men was especially important. This distribution can be seen in Figure 2 .

The data from frequency of journey was grouped into occasional users, once or twice a week users, three or four times a week users and daily users. The results in the graph in Figure 3 show that almost half the users of interurban bus services were occasional. Nevertheless, looking only at the female data, the percentage of occasional users was slightly smaller, but there was a greater percentage of 'daily' users. Finally, it is worth noting that the average number of times per month that the interviewees used the service was 7.8 for the overall data, 8.2 for women and $7 \cdot 1$ for men, reflecting again that women used the service more frequently than men.

Finally, the data on length of journey were divided into the 


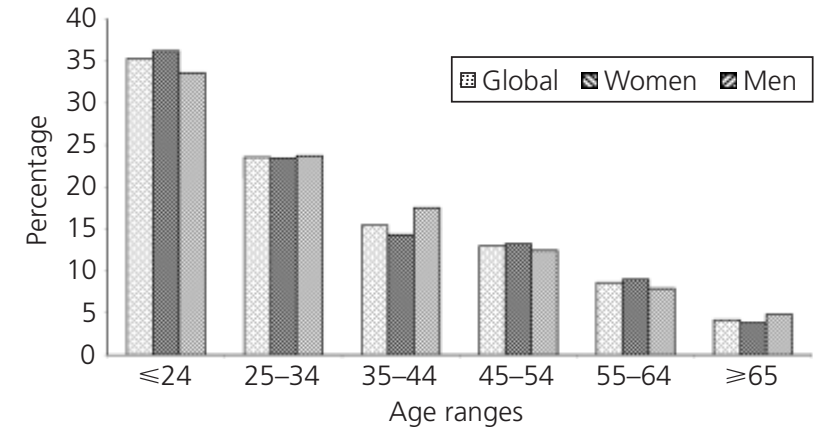

Figure 2. Distribution of interviewees by age ranges

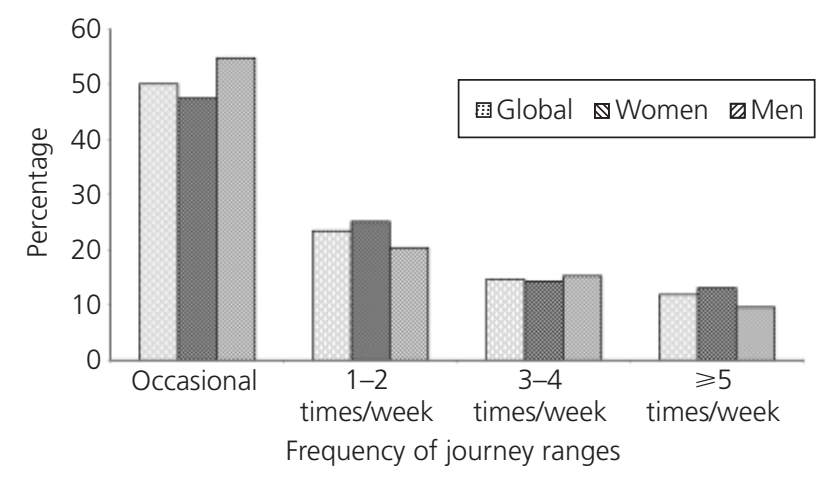

Figure 3. Distribution of interviewees into frequency of journey ranges

following ranges: $\leqslant 30 \mathrm{~km},>30$ to $\leqslant 100 \mathrm{~km},>100$ to $\leqslant 250 \mathrm{~km}$ and $>250 \mathrm{~km}$; these ranges are represented in Figure 4. The average trip length was $109 \mathrm{~km}$ for the overall data, $99 \mathrm{~km}$ for women and $127 \mathrm{~km}$ for men, once again showing different behaviour between men and women, the latter using the public transport service more frequently but for shorter trips, whereas men tend to use the service more occasionally yet for longer journeys.

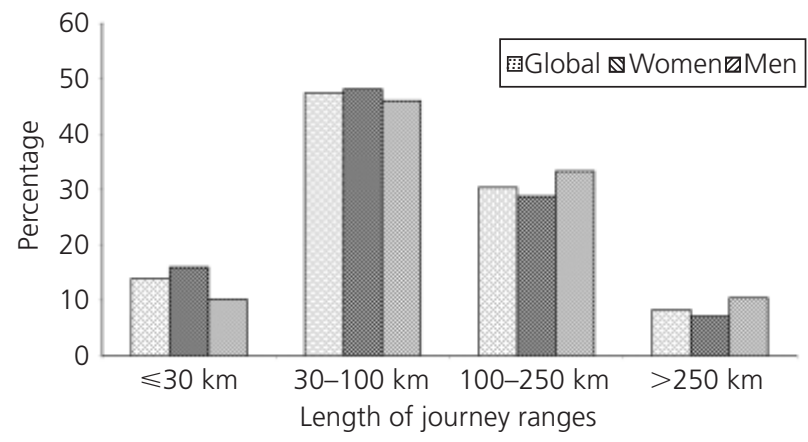

Figure 4. Distribution of interviewees by length of journey ranges

\section{Ordinal model development}

Following the methodology outlined above, a total of 1319 surveys were carried out with public bus users in order to find out how they valued the service both from an overall perspective and relative to individual variables. Only 1011 of these surveys were complete and finally selected for the model elaboration.

As the data were ordered ('very good' is better than 'good', which is better than 'average'), a better way to introduce them into a discrete choice model was through using ordered types. The alternatives were not independent, so to apply a standard logit model would not be following correct methodology. Train (2003) considers that ordered models are better for this type of data than probit, which are not a natural way of modelling interviewees' decisions.

In ordered type models, it is assumed that each interviewed person has an unobservable utility function of his/her overall satisfaction about the service, called $Y_{j}$ ( $j$ from 1 to $n$ ). Higher values of $Y_{j}$ represent a better perceived quality. In the survey performed as part of the present study, the interviewed person was asked to fit his/her opinion $Y_{j}$ into one of the five presented categories $Z_{j}$ (Table 1).

It was assumed that this variable satisfied a linear model (Ortúzar and Garrido, 2000), so $Y_{j}$ can be expressed as:

1. $Y_{j}=X_{j} \theta+\varepsilon_{j}$

where $X_{j}$ is a $K$-dimensional vector of independent variables (attributes); $\theta$ is a $K$-dimensional vector of model coefficients; $\varepsilon_{j}$ is a random error (their distribution determines the probability of the five possible responses, and the type of the ordered model).

$Z_{j}$ is an ordinal version of the actual values of $Y_{j}$ which does not verify the linear model.

If $Z_{j}$ has $M$ possible responses $R_{1}, R_{2}, \ldots, R_{M}$, and $\mu_{0}, \mu_{1}, \ldots$, $\mu_{M}$ are $M+1$ real numbers where $\mu_{0}=-\infty$ and $\mu_{M}=+\infty$, it is assumed that these numbers satisfy: $\mu_{0} \leqslant \mu_{1} \leqslant \ldots$ $\leqslant \mu_{M-1} \leqslant \mu_{M}$. So that:

2. $Z_{j} \in R_{m} \Leftrightarrow \mu_{m-1} \leqslant Y_{j} \leqslant \mu_{m}$ for $1 \leqslant j \leqslant n$

As $Z_{j}$ is an ordinal variable, it is represented by a set of dummy variables, as follows:

3. $Z_{j m}\left\{\begin{array}{l}1 \text { if } Z_{j} \in R_{m} \\ 0 \text { otherwise }\end{array}\right.$ for $1 \leqslant j \leqslant n, \quad 1 \leqslant m \leqslant M$ 
On the other hand, the presented expressions allow the probability function of the observed variable, $Z_{j}$, to be defined as follows:

$$
\begin{aligned}
& \text { for } 1 \leqslant j \leqslant n, \quad 1 \leqslant m \leqslant M \Rightarrow \\
& \operatorname{Prob}\left(Z_{j m}=1\right)=\operatorname{Prob}\left(Z_{j} \in R_{m}\right) \\
= & \operatorname{Prob}\left(\mu_{m-1} \leqslant Y_{j} \leqslant \mu_{m}\right) \\
= & \operatorname{Prob}\left(\mu_{m-1} \leqslant \sum_{k=1}^{K} \theta_{k} X_{k j}+\varepsilon_{j} \leqslant \mu_{m}\right) \\
= & \operatorname{Prob}\left(\frac{\mu_{m-1}-\sum_{k=1}^{K} \theta_{k} X_{k j}}{\sigma} \leqslant \frac{\varepsilon_{j}}{\sigma} \leqslant \frac{\mu_{m}-\sum_{k=1}^{K} \theta_{k} X_{k j}}{\sigma}\right) \\
= & \operatorname{Prob}\left(\frac{\varepsilon_{j}}{\sigma} \leqslant \frac{\mu_{m}-\sum_{k=1}^{K} \theta_{k} X_{k j}}{\sigma}\right) \\
& -\operatorname{Prob}\left(\frac{\varepsilon_{j}}{\sigma} \leqslant \frac{\mu_{m-1}-\sum_{k=1}^{K} \theta_{k} X_{k j}}{\sigma}\right)
\end{aligned}
$$

Finally, as any linear transformation of the unobservable variable $Y_{j}$ applied to the series $\mu m$ yields exactly the model, it can be assumed that $\mu_{1}=0$ and $\sigma=1$ in order to identify the final model coefficients (Ortúzar and Garrido, 2000). Thus, the calibration problem consists of estimating the $M+K-2$ coefficients $\mu_{2}, \ldots, \mu_{M-1}, \theta_{1}, \ldots, \theta_{K}$, through the maximisation of the log-likelihood function.

Once a distribution for the error term is specified, the probabilities can be calculated exactly (Train, 2003). If it is assumed that the error term follows a logistic distribution with zero mean and covariance matrix $\sigma^{2} \mathrm{I}$ (I is the identity matrix), the resulting model is called 'ordered logit'. In this case, solving the problem is simple:

$$
\begin{aligned}
\operatorname{Prob}\left(Z_{j m}=1\right)= & \operatorname{Prob}\left(Z_{j} \in R_{m}\right) \\
= & \frac{\mathrm{e}^{\mu_{m}-\sum_{k=1}^{K} \theta_{k} X_{k j}}}{1+\mathrm{e}^{\mu_{m}-\sum_{k=1}^{K} \theta_{k} X_{k j}}} \\
& -\frac{\mathrm{e}^{\mu_{m-1}-\sum_{k=1}^{K} \theta_{k} X_{k j}}}{1+\mathrm{e}^{\mu_{m-1}-\sum_{k=1}^{K} \theta_{k} X_{k j}}}
\end{aligned}
$$

It is interesting to note that the probabilities in the ordered logit model follow the binary logit equation. Nevertheless, the main difference is that binary logit specifies two alternatives with one utility each, whereas an ordered logit model has only one utility function with multiple alternatives to represent the level of that utility. Thus, this similarity is only 'incidental', as Train (2003) notes.

Under the assumption that the error term follows a normal rather than logistic distribution, Zavoina and McElvey (1975) developed the 'ordered probit' model. In this case:

$$
\begin{aligned}
\operatorname{Pr}\left(Z_{j m}=1\right)= & \operatorname{Pr}\left(Z_{j} \in R_{m}\right) \\
= & \varphi\left(\frac{\mu_{m}-\sum_{k=1}^{K} \theta_{k} X_{k j}}{\sigma}\right) \\
& -\varphi\left(\frac{\mu_{m-1}-\sum_{k=1}^{K} \theta_{k} X_{k j}}{\sigma}\right) \\
= & \ldots(\text { considering } \sigma=1) \ldots \\
= & \varphi\left(\mu_{m}-\sum_{k=1}^{K} \theta_{k} X_{k j}\right) \\
& -\varphi\left(\mu_{m-1}-\sum_{k=1}^{K} \theta_{k} X_{k j}\right)
\end{aligned}
$$

where $\varphi(\cdot)$ is the standard cumulative normal function.

For more information about these models, their calibration process and some statistics associated with their development, see Ortúzar and Garrido (2000), Train (2003), Zavoina and McElvey (1975), Ierza (1985), Johnson (1990), dell'Olio et al. (2009, 2010) and Ibeas et al. (2009).

\section{Application and results}

This section presents the results obtained for the different models tested, relating the overall satisfaction of interurban bus users with the service variables.

The best models for each type are presented. These models are ordered logit and probit; the one that gave the best fit was chosen in each case. They produced the most significant variables (at a $95 \%$ confidence level) both by considering all the data and disaggregating it by sex.

Figure 1 includes all the variables used in the survey, as well as their distribution by category. The service variables are grouped into the following categories: ticket sales, timetable, bus comfort and route. The variables on individual characteristics were not included in the modelling because the aim was to produce models with equal parameters for all users. The best of these should then be able to help elaborate the methodology for detecting priority of action for each variable, as shown in Section 6, where there can only be a single value for each parameter. 


\subsection{Global model}

This section presents the results of the models elaborated with all the data collected in the surveys.

The ordered logit and probit models contributing the best results are presented in Table 2. Only variables that were statistically significant at a $95 \%$ confidence level were considered.

From the table, it can be concluded that the relation qualityprice was the most relevant variable for all the users of interurban public transport by bus. In the ordered logit model, the second most relevant variable was the condition of the bus followed by road safety and frequency of service. In the ordered probit model, the variables by importance were the condition of the bus, the frequency of service and information on bus times.

Note that, in the ordered probit model, the data had to be transformed because of the high number of iterations. The evaluation scale was reduced from a 1 to 5 scale to 1 to 3 : valuations 1 and 2 were turned into 1 ('bad'), valuation 3 was transformed to 2 , and valuations 4 and 5 were considered as a 3 ('good').

The difference between models can be explained by the change in the scale of the variables. So, the first conclusion is that ordered logit presented a better fit than ordered probit because the data were not transformed in the former.

\subsection{Female and male models}

As in the previous section, both ordered logit and probit models were elaborated, but this time including data on the sex of the interviewed person.

The results of the ordered logit and probit models with best fit are presented in Table 3. As in the previous table, the first number is the estimation of the parameter of the utility function and the number in brackets is the T-ratio indicating the level of statistical significance of the variable.

\begin{tabular}{lcc}
\hline Parameter & Ordered logit & Ordered probit \\
\hline Ease of purchase (ticket) & $0 \cdot 18596846(2 \cdot 167)$ & $0 \cdot 15385233(2 \cdot 677)$ \\
Punctuality & $0 \cdot 23998676(3 \cdot 315)$ & - \\
Information on bus times & $0 \cdot 22277584(3 \cdot 169)$ & - \\
Frequency of service & $0 \cdot 26418087(3 \cdot 962)$ & $0 \cdot 15749670(2 \cdot 861)$ \\
State of upkeep (condition of the bus) & $0 \cdot 39151246(4 \cdot 351)$ & - \\
Cleanliness (bus) & $0 \cdot 25062524(2 \cdot 562)$ & $0 \cdot 14791741(2 \cdot 258)$ \\
Temperature (bus) & $0 \cdot 25941009(3 \cdot 004)$ & $0 \cdot 14038816(2 \cdot 192)$ \\
Seat comfort (bus) & - & $0 \cdot 14014168(2 \cdot 149)$ \\
Noise (bus) & - & - \\
Space between seats (bus) & $0 \cdot 17051331(2 \cdot 406)$ & - \\
Journey time & $0 \cdot 17520831(2 \cdot 237)$ & - \\
Safety & $0.31449700(3.658)$ & $0 \cdot 11900636(2 \cdot 080)$ \\
Number of stops & $0 \cdot 26233086(3 \cdot 706)$ & $0 \cdot 48572589(7 \cdot 918)$ \\
Relation quality-price & $0.67985939(8 \cdot 341)$ & Ordered probit \\
\hline Threshold parameter & Ordered logit & $2 \cdot 00677432(20 \cdot 942)$ \\
\hline Mu (1) & $5 \cdot 14466811(30 \cdot 952)$ & - \\
Mu (2) & $8 \cdot 86616772(68 \cdot 205)$ & - \\
\hline Mu (3) & $12 \cdot 7948791(72 \cdot 418)$ & - \\
\hline
\end{tabular}

\section{Model data}

Number of observations

Iterations completed

Log-likelihood function

Restricted log likelihood

Chi-squared

Degrees of freedom

Ordered logit

1011
23
$-813 \cdot 5562$
$-1174 \cdot 547$
$721 \cdot 9814$
11

1011

12

$-675 \cdot 2409$

$-904.5482$

458.5482

7

Table 2. Global ordered logit and probit models 


\begin{tabular}{|c|c|c|c|c|}
\hline \multirow[t]{2}{*}{ Parameter } & \multicolumn{2}{|c|}{ Ordered logit } & \multicolumn{2}{|c|}{ Ordered probit } \\
\hline & Women & Men & Women & Men \\
\hline Ease of purchase (ticket) & $0 \cdot 24259605(2 \cdot 208)$ & - & - & - \\
\hline Punctuality & $0.25202091(2 \cdot 825)$ & - & - & - \\
\hline Information on bus times & $0 \cdot 19467554(2 \cdot 127)$ & $0.33275421(3.099)$ & - & $0 \cdot 25342680(2 \cdot 818)$ \\
\hline Frequency of service & $0.40875538(4.907)$ & - & $0.23143516(3 \cdot 561)$ & - \\
\hline $\begin{array}{l}\text { State of upkeep (condition of the } \\
\text { bus) }\end{array}$ & $0 \cdot 48082596(4 \cdot 319)$ & - & $0 \cdot 34225985(4 \cdot 109)$ & - \\
\hline Cleanliness (bus) & - & $0.44102023(2.947)$ & - & $0.39853202(4.097)$ \\
\hline Temperature (bus) & $0 \cdot 34013228(3 \cdot 125)$ & $0.29980953(2 \cdot 256)$ & - & - \\
\hline Seat comfort (bus) & $0 \cdot 31767848(3 \cdot 014)$ & - & $0 \cdot 20229966(2 \cdot 587)$ & - \\
\hline Noise (bus) & - & $0.33227927(2.607)$ & $0.18403309(2.329)$ & - \\
\hline Journey time & - & $0 \cdot 31633162(2 \cdot 457)$ & - & $0 \cdot 21956238(2 \cdot 354)$ \\
\hline Safety & $0.42134904(3.795)$ & - & - & - \\
\hline Number of stops & $0.29199992(3.412)$ & $0.29330517(2 \cdot 470)$ & $0 \cdot 17035312(2 \cdot 490)$ & - \\
\hline Relation quality-price & $0.65058862(6.566)$ & $0.76225070(5.423)$ & $0.44417892(5.955)$ & $0.57096866(5.422)$ \\
\hline Threshold parameter & Women & Men & Women & Men \\
\hline $\mathrm{Mu}(1)$ & $5 \cdot 50188935(25 \cdot 681)$ & $3.49549706(13.971)$ & $1.97130720(16 \cdot 522)$ & $2 \cdot 04033410(12 \cdot 996)$ \\
\hline $\mathrm{Mu}(2)$ & $9 \cdot 26018471(53 \cdot 716)$ & $7 \cdot 20212347(36 \cdot 070)$ & - & - \\
\hline $\mathrm{Mu}(3)$ & $13 \cdot 4502267(56 \cdot 707)$ & $10 \cdot 7359726(40 \cdot 079)$ & - & - \\
\hline Model data & Women & Men & Women & Men \\
\hline Number of observations & 657 & 354 & 657 & 354 \\
\hline Iterations completed & 21 & 17 & 10 & 8 \\
\hline Log-likelihood function & $-510 \cdot 1692$ & -301.9559 & $-431 \cdot 8604$ & $-241 \cdot 7473$ \\
\hline Restricted log-likelihood & -756.9948 & $-416 \cdot 2123$ & $-580 \cdot 5669$ & $-322 \cdot 7562$ \\
\hline Chi-squared & $493 \cdot 6512$ & $228 \cdot 5127$ & $297 \cdot 4130$ & $162 \cdot 0177$ \\
\hline Degrees of freedom & 9 & 6 & 5 & 3 \\
\hline
\end{tabular}

The results of the model show that the variable relation qualityprice was the most important for both sexes.

The ordered logit model shows the variables coming next in importance for women were the condition of the bus, road safety and frequency of service (which coincide with the order obtained for the global ordered logit model). On the other hand, for men, cleanliness, information on bus times and the noise in the bus followed in importance after quality-price.

The same transformation as before was used for the ordered probit model, reducing the scale from 1 to 5 to 1 to 3 . In this case, the variables following quality-price in importance were, for women, the condition of the bus and the frequency of service and, for men, cleanliness and information on bus times.

The difference between the results of both models was again due to the transformation carried out on the scores assigned to each variable. It is for that reason that, in principle, the results of the ordered logit model seem to be more accurate because none of the data obtained in the surveys was eliminated.

\section{Comparison importance-evaluation for the female model}

This section presents a brief comparison between the direct individual evaluation of each variable with the importance assigned to them, from the models estimated using the data on women.

The variables considered were those that were significant for the ordered logit model, being a total of 10 .

As proposed by the Chicago Transit Authority (Foote and Stuart, 1998), the interaction between influence (T-ratio statistic) and evaluation (average level, from 1 to 5) can be represented graphically. The horizontal axis is the T-ratio statistic of the linear 
regression model and the vertical axis is the average evaluation of the perceptions of the users in the survey. The graph is presented in Figure 5.

Following the methodology proposed in Foote and Stuart (1998), the graphic area is divided into four zones, by vertical and horizontal lines in the middle of each axis. In the present case, the $T$-ratio axis middle value is about 4.35 and the middle value in the vertical axis is $3 \cdot 85$. So, the following zones could be identified.

(a) Zone 1 contains the variables with highest priority for action, since they are the most relevant and worse scored. In the present case, these variables were the quality-price relationship and the frequency of service.

(b) Zone 2 contains variables with a good score that need to be maintained because they are of importance to the users. In the present case this zone was empty.

(c) Zone 3 contains variables whose improvement would be beneficial, because, although they are of relatively little importance, they are badly scored. In the present case, these variables were punctuality, number of stops, temperature, condition of the bus and seat comfort.

(d) Zone 4 has low priority variables, since they have relatively little importance and, in addition, they already have higher scores. These variables were road safety, ease of ticket purchase and information on bus times.
A similar graph can also be created to represent the influence of each variable, not considering the $T$-ratio, rather the estimation of the associated parameter of the utility function. The results were slightly different: the vertical scale was the same and only the horizontal axis changed (medium value of $0 \cdot 42$ ).

The zoned results are listed here.

(a) Zone 1. The quality-price relationship and frequency of service are the most prioritised variables.

(b) Zone 2. Road safety is another high-priority variable because it remains important and must keep its high average evaluation value.

(c) Zone 3. The variables contained in this zone are punctuality, number of stops, frequency of service and temperature and seat comfort on the bus.

(d) Zone 4 . The lowest priority variables are ease of ticket purchase and information on bus times.

Finally, a new method is proposed. A new type of graphic division is elaborated using diagonal lines. Each line has the slope of the absolute diagonal of the rectangle delimited by the represented data. The absolute diagonal of the rectangle divides it into two equal triangles. Each triangle is divided again by another parallel diagonal line into two subzones with the areas shown in Figure 6.

This new methodology determines different degrees of priority of

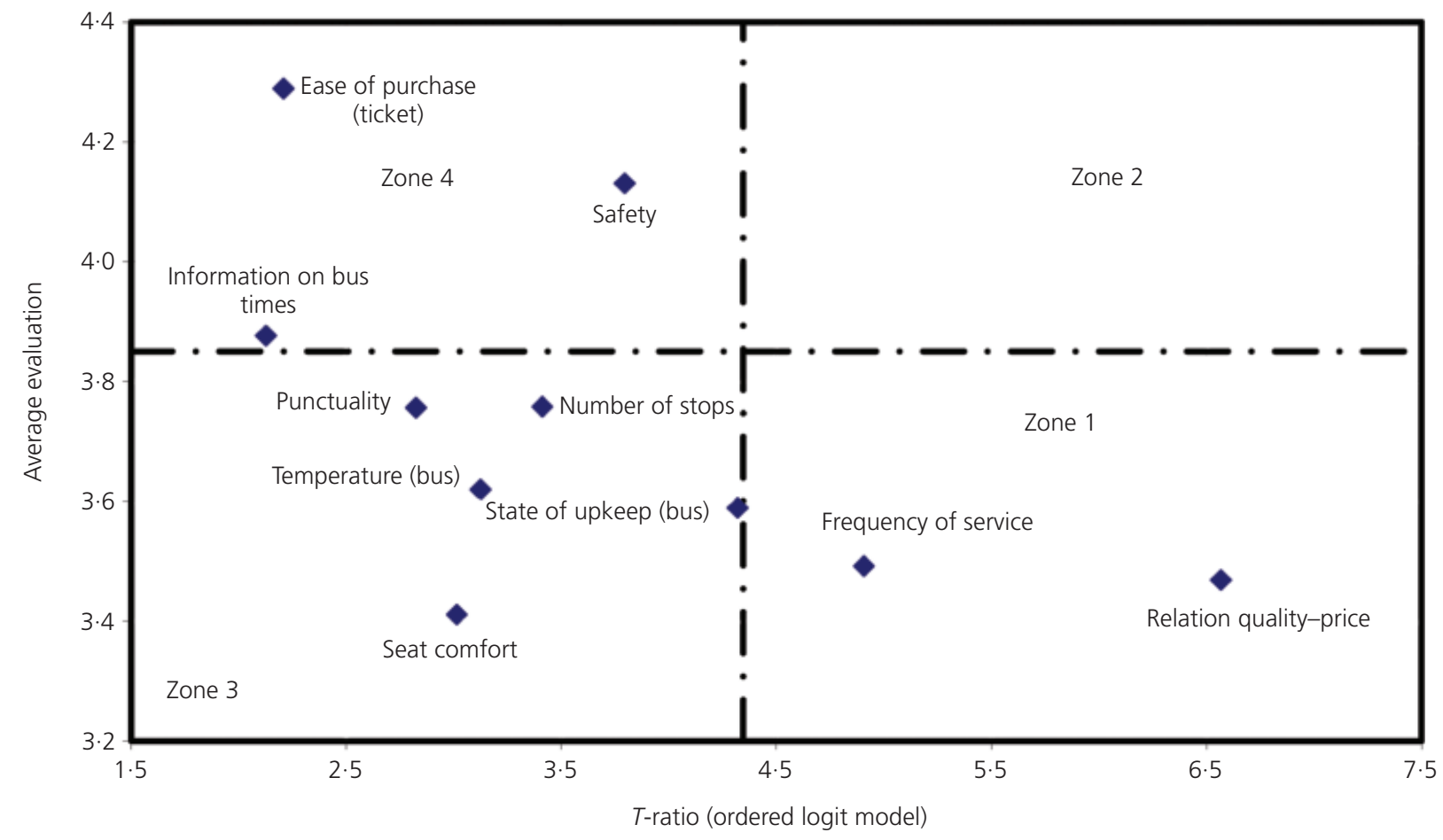

Figure 5. Comparison statistical significance-evaluation 


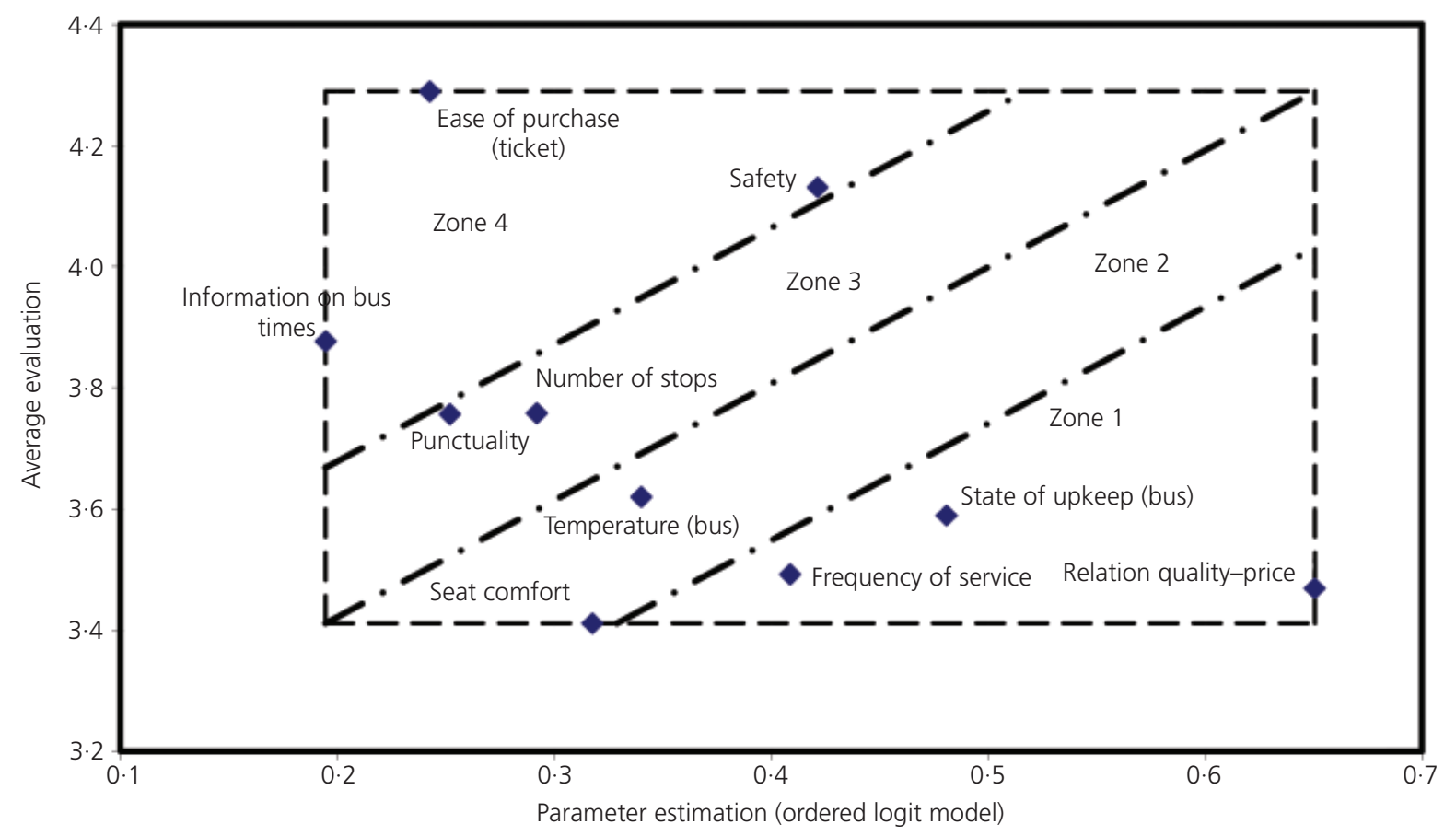

Figure 6. Comparison influence-evaluation (with diagonal division)

action. The zone located in the lower right corner is 1 , and the one in the upper left corner is 4 . This new distribution of zones prioritises the service variables in the following manner.

(a) Zone 1 . The high priority variables are the relation qualityprice, the condition of the bus and the frequency of service.

(b) Zone 2. The next priority variables are the temperature and the seat comfort of the bus.

(c) Zone 3. Variables which are not high priority are punctuality and the number of stops.

(d) Zone 4. The least priority variables are ease of ticket purchase, information on bus times and road safety (close to zone 3).

The priority for action of the considered variables is more adjusted to their relationship between influence and evaluation. This type of division avoids the problem of variables being close to a division line (see variable safety in Figure 5) between two zones with opposite priorities. Figure 6 shows that the zones progress in priority, so if a variable is near a division line, the priority of action is similar.

In addition, these zones can also be subdivided, always giving more priority to the zones located in the right inferior part of the graph; or curve the dividing lines between the zones (determined with a mathematical equation), with a concave form towards the lower right and upper left corners of the graph.
The results of this alternative methodology can be used as part of transport policy. The objective would be to find a working point for the system where the variables were above the main diagonal on the graph. In the present case, priority should be given to reducing the cost of the fare, renewing the bus fleet and increasing the frequency of service.

This same methodology can be applied to other types of surveys on quality in which the users are asked about their overall level of satisfaction and evaluation of each variable. This allows action to be taken on individual parameters which are really relevant to the users, thereby optimising the use of available resources and improving the efficiency of the public transport system.

\section{Conclusions}

The level of user satisfaction with public bus services depends on many variables, some of which are more important than others and these are the ones that need to be known and improved in order to encourage the use of public transport. The influence of these variables on user perception of service quality changes depending on the personal circumstances of each user.

In general, the variable which affected users the most was the relationship between quality and price, followed by other important parameters such as the condition of the bus and the frequency of service. 
The main differences between men and women appeared for certain variables such as road safety, seat comfort on the bus and punctuality, which women appreciated most. On the other hand, men valued variables such as journey time, noise and cleanliness in the bus.

A new methodology has been proposed for detecting the service variables with the highest priority to act on, based on a graphical representation of the relationship between their influence in the overall satisfaction model and their average value. It has been shown that the highest priority variables for women were the relation quality-price, the condition of the bus and the frequency of service, followed by seat comfort and the temperature in the bus. On the other hand, the variables with the least priority were the ease of ticket purchase, information on bus times and road safety (which is highly evaluated).

The main characteristics that define the behaviour of female users of interurban bus services have been determined. The proportion of users diminished as age increased. Women seemed to use the service more frequently, for shorter trips, whereas men tended to occasionally use the service, but for longer journeys.

Finally, a successful modelling exercise was carried out on overall user satisfaction depending on their personal characteristics and dividing the global data by sex and the quality of each of the considered service variables. This analysis can therefore be seen as a useful tool for improving public bus services and optimising available resources with the objective of promoting a more sustainable transport system and improving the quality of life on the roads.

\section{Acknowledgements}

The authors acknowledge the invaluable awareness and concern for promoting interurban public transport shown by the Innovation and Formation Section of the General Directorate of Transport of the Castilla y León Government and thank their support in doing the survey.

The authors also appreciate the collaboration of the Education Council of the Castilla y León Government and the European Social Fund, through their Formation of Researcher Personnel Aids in the Community of Castilla y León.

\section{REFERENCES}

Balcombe R, Mackett R, Paulley N, Preston J, Shires J, Titheridge H, Wardman M and White P (2004) The Demand for Public Transport: a Practical Guide. Transport Research Laboratory, Wokingham, UK, Report TRL593.

Cherniack N (1981) Transit subsidies can be reduced ... quality bus transit could be profitable. ITE Journal 51(8): $37-40$.

dell'Olio L, Ibeas A and Moura JL (2009) Paying for parking: improving stated-preference surveys. Proceedings of the Institution of Civil Engineers - Transport 162(1): 39-45.
dell'Olio L, Ibeas A and Cecín P (2010) Modelling user perception of bus transit quality. Transport Policy 17(6): 388-397.

Foote PJ and Stuart DG (1998) Customer satisfaction contrasts express versus local bus service in Chicago's north corridor. Transportation Research Record 1618: 143-152.

Foote PJ, Stuart DG and Elmore-Yalch R (2001) Exploring customer loyalty as a transit performance measure. Transportation Research Record 1753: 93-101.

Glascock J (1997) Research on customer requirements for transit service design and delivery. Transportation Research Record 1604: $121-127$.

Hamilton K and Jenkins L (2000) A gender audit for public transport: a new policy tool in the tackling of social exclusion. Urban Studies 37(10): 1793-1800.

Hensher DA and Houghton E (2004) Performance-based quality contracts for the bus sector: delivering social and commercial value for money. Transportation Research Part B 38(2): 123146.

Hensher DA and Stanley J (2003) Performance-based quality contracts in bus service provision. Transportation Research Part A 37(6): 519-538.

Hensher DA, Stopher P and Bullock P (2003) Service quality developing a service quality index in the provision of commercial bus contracts. Transportation Research Part A 37(6): 499-517.

Ibeas A, dell'Olio L, González F and Moura JL (2009) Cost benefit analysis of town centre car park. Proceedings of the Institution of Civil Engineers, Municipal Engineering 162(1): 41-50.

lerza JV (1985) Ordinal probit: a generalization. Communications in Statistics - Theory and Method 14(1): 1-11.

Johansson-Stenman O (2002) Estimating individual driving distance by car and public transport use in Sweden. Applied Economics 34(8): 959-967.

Johnson LW (1990) Discrete choice analysis with ordered alternatives. In Spatial Choices and Processes (Fisher MM, Nijkamp P and Papageorgiou YY (eds)). North Holland, Amsterdam, the Netherlands, pp. 279-289.

Matthies E, Kuhn S and Klöckner CA (2002) Travel mode choice of women: the result of limitation, ecological norm, or weak habit? Environment and Behavior 34(2): $163-177$.

Nurdden A, Rahmat RAOK and Ismail A (2007) Policies to coerce car drivers to utilize public transportation (for all trips and school trips) in Malaysia. European Journal of Scientific Research 16(4): 596-605.

Ortúzar J de D and Garrido RA (2000) An application of ordinal probit to SP rating data. In Stated Preference Modelling Techniques (Ortúzar J de D (ed.)). PTRC Education and Research Services, London, pp. 103-120.

Pazy AA, Salomon IB and Pintzov TC (1996) The impacts of women's careers on their commuting behavior: a case study of Israeli computer professionals. Transportation Research Part A: Policy and Practice 30(4): 269-286. 
Schmucki BA (2002) On the trams: women, men and urban public transport in Germany. Journal of Transport History 23(1): $60-72$.

Train K (2003) Discrete Choice Methods with Simulation.

Cambridge University Press, Cambridge, UK.

Wen CH, Lan LW and Cheng HL (2005) Structural equation modeling to determine passenger loyalty toward intercity bus services. Transportation Research Record 1927: 249255.

Zavoina R and McElvey W (1975) A statistical model for the analysis of ordinal level dependent variables. Journal of Mathematical Sociology 4(1): 103-120.

\section{WHAT DO YOU THINK?}

To discuss this paper, please email up to 500 words to the editor at journals@ice.org.uk. Your contribution will be forwarded to the author(s) for a reply and, if considered appropriate by the editorial panel, will be published as a discussion in a future issue of the journal.

Proceedings journals rely entirely on contributions sent in by civil engineering professionals, academics and students. Papers should be 2000-5000 words long (briefing papers should be 1000-2000 words long), with adequate illustrations and references. You can submit your paper online via www.icevirtuallibrary.com/content/journals, where you will also find detailed author guidelines. 